\title{
Correspondence
}

\section{On a Comparative Sociology of India: A Reply to Marriott}

We are puzzled by Marriott's response to our discussion of his work; he criticizes us for an article we explicitly avoided writing, one citing numerous sources. ${ }^{1}$ We are quite familiar with the items in Marriott's footnotes and while we do not question his learning we do question his assumptions, interpretations, and theories which are independent of the contributions of others. It is not the "accuracy" (whatever that is) of Marriott's "facts" that disturbs us. We objected to (and continue to object to in the absence of any arguments to the contrary) the epistemology, methodology, and understanding provided us in Marriott's works. We did not merely review an article by Marriott and Inden; we contributed a critique of alternatives (among them Marriott's monist opus to date) to Dumont's comparative sociology. That Marriott offers a challenge to comparative sociology, that he is concerned with Hindu transactions without duality, that he provides a curious brand of monism is not our invention; his own reply is proof enough.

Our critique was written with a dual purpose: to transcend the often petty level of the debate surrounding Homo Hierarchicus and to evaluate alternatives to Dumont's approach. In the course of our discussion we indicated ways in which we can go beyond the controversies raised by Dumont and tackle the coming tasks of Indian sociology. Since Marriott has yet to respond to our detailed criticism of his work and since he chose to make a more general defense of his position we raise a number of problems for his monism:

I. We do not think that the old debate between monism and dualism in Western philosophy is relevant to our discussion. That debate concerned the unity or separation of mind and matter, a question neither we nor Dumont have referred to.

2. By laying claim to monism in general Marriott merely succeeds in bringing philosophical confusion to the discussion. Of course we do not challenge the fundamental unity of India nor the relational unity of mind and matter (well stated in contemporary structural and systems theories in reference to hierarchical as well as other relationships). A dualism of mind and matter we cannot accept since our "dualism" refers to relation. ships, methodology, and epistemology, not substance and content (which Marriott's monism most definitely implies).

3. We challenge specifically Marriott's own version of "monism" which would postulate that not only is the subject one but all is one-a questionable progression since it pretends the same kind of monism to our discipline as Marriott claims for India, bringing the two together in such a fashion that no sociology, no theory, and indeed no understanding is possible. We object to this kind of monism as an impossible interpretive

\footnotetext{
${ }^{1}$ Steve Barnett, Lina Fruzzetti, and Ákos Östör, "Hierarchy Purified: Notes on Dumont and His Critics," JAS, XXXV, 4 (1976), pp. 627-46;
}

McKim Marriott, "Interpreting Indian Society: A Monistic Alternative to Dumont's Dualism," $J A S$, XXXVI, 1 (1976), pp. 189-95. 
process that is at best a reduction to direct intuitionism. Failing to realize this, Marriott comes to perceive himself in his work as a part of his subject, aggregating to himself all fields of study until self becomes coextensive with the subject.

4. Marriott's monist view seems to suggest that only a concept of "dividuals" plus the notion that all aspects of Indian life are coded into interchangeable monad-like particles that move in and among individuals are necessary to present an indigenous Indian culture. Against that, we suggest these dividuals (encompassed persons) must still be situated in a holistic ideology that accounts for the segmentary nature of Indian society through an understanding of relations. This segmentation is introduced in an ad hoc fashion by Marriott as arbitrary clusters of types and amount of particles present.

5. It is an epistemological error to suppose that we can ever present an unvarnished indigenous culture; we can only compare and contrast, the most immediate (and problematic from Marriott's perspective, since it forms a self-reflective paradox) issue being the relation between the anthropologist and those studied. Not being content to recognize the unity of India as a part of the data to be understood and interpreted, Marriott takes monism to be a self-evident truth. Yet, as with ethnomethodologists, Marriott's privileged access to subjective meaning is not provided a method for directly apprehending Indian "Hindu Culture." It is doubtful that monism of this kind ever played a significant role in Indian history.

6. What Marriott calls Dumont's "dualism" is a relation between ideas and action (nothing to do with spirit and matter) and a relation between the "West" and India. If this is meant by dualism then we also plead guilty, for indeed sociological knowledge is constituted through the interplays we noted above (and in our critique), but then the alternative is no sociology at all.

7. In his confusion between "early" and "late" Dumont, Marriott proves valid some of the above strictures. First, he does not distinguish between a sociological view of India (the popular representations) and a specialized set of representations (systems of medicine, astrology, philosophy are all assimilated to the "Hindu" view). Second, he comes close to providing a new version of theosophy (India is all; we have to become like them to understand them). Third, the quotation (out of context) from Dumont's essay on Kingship in fact says something quite different. ${ }^{2}$ Marriott's procedure is characteristic: Dumont here argues for the special position of the King as a political actor (hence the Smriti text on this point is not normative, implying that texts in other respects are indeed normative). Dumont's argument here is consistent with his later position (as is his use of texts in a context and as a structural parallel-not as an authority that can be quoted across space and time but as an item of data to be established through analysis).

8. Marriott transforms Indian culture into a world of monad-like substances, each interacting with others, but preserving intact its prior substantial quality. These substances form clusters simply by aggrandizement, weight, and volume, and these clusters somehow become castes, lines, political factions, varnas. A comparative view on the other hand stresses that prior relational context necessary to understanding Indian society and focuses on the development of segmentation as hierarchy structured in the first instance by relative purity. Without hierarchical segmentation, Marriott can accuse us of making an "encompassed exception" of Hindus who eat meat. But this is precisely the sub. stantialist error; meat-eating becomes a substantial quality apart from a particular

\footnotetext{
${ }^{2}$ Louis Dumont, "'The Conception of Kingship in
}

Ancient India," Contributions to Indian Sociology, 6 (1962), pp. 48-77. 
relational context-rather one does what is appropriate given a set of relations, here a position in the segmentary order of caste.

9. Marriott's monist view sees contemporary developments in Indian society (especially in caste organization) as completely understandable within this version of traditional Indian culture (dividuals plus particles). This fundamentally obscures the possibility and development of a structural transformation in the ideology of caste when caste becomes intertwined with the nation-state, and with class, ethnic-like, and racial antagonisms. Monist analysis has not found anything significant to say about twentieth-century caste except perhaps that it is culturally identical to ancient caste.

Io. Marriott fails to understand structuralism and, although Western dualism is castigated, it is clear Marriott has Lévi-Strauss's oppositions in mind. In this regard we recommend a perusal of Roman Jakobson's work with its unmistakable insistence on relations between variants and invariants, universals and particulars, dynamic relations in a structure, changes over time, and (once again!) hierarchy as a fundamental relationship in the scientific study of signs, semiotics. Let us also recall that among relationships there may be opposition, overlap, contradiction, complementarity, and exclusion, as well as hierarchy.

II. It is commendable to question Western thought so long as this attitude results in a critique and not subjective rejection: our position should not be one of revulsion with the "West" but a reciprocal understanding of India and the West at all levels of our disciplinary endeavor. Ironically the very name (monism) in which Marriott makes his plea has a long and checkered Western career which he has yet to discuss.

12. There is no doubt that Marriott does not account for his own approach since he does not tell us how it is constituted (cf. Wagner's exposition of fieldwork as the "invention" of culture ${ }^{3}$-Marriott's "culture" is a concrete substance that can be assembled out of discrete particles). Marriott does not exhibit a sociological apperception of man: incapable of seeing himself as a social being, his monism becomes an extreme case of Western individualism to the extent that the investigator's own being becomes coextensive with that of all India and all Indians. A comparative approach on the other hand avoids Marriott's sort of cosmic statements by sticking to the business at handunderstanding that which we are partially without and partially within, and not sacrificing one for the other as scientism or simply "going native."

STEVE Barnett

LiNA M. FRUZZETTI ÁKOS ÖSTÖR

\section{Providence, Rbode Island}

${ }^{3}$ Roy Wagner, The Invention of Culture (Englewood Cliffs, N.J.: Prentice-Hall, 1975).

\section{A Reply to H. Lyman Miller's Review of Ruling from Horseback}

One looks forward to reviews in the Journal of Asian Studies because they usually contain high-level scholarly analyses. I was somewhat disheartened, therefore, that Miller's sharply critical review of my own book (JAS, XXXVI [1976], p. 130) failed to address its central themes concerning seventeenth-century Chinese politics. Instead, Miller seemed obsessed with side issues and footnotes. 